\title{
Tractive Performance of LGP-30 Wheeled Vehicle During Straight Motion on Sepang Peat Terrain in Malaysia
}

\author{
Ataur Rahman ${ }^{*}$, , Azmi Yahya ${ }^{2}$, and A.K.M. Mohiuddin ${ }^{1}$ \\ ${ }^{I}$ Department of Mechanical Engineering (Mechanical-Automotive Engineering), Faculty of Engineering, International \\ Islamic University Malaysia (IIUM), 50728 Kuala Lumpur, Malaysia \\ ${ }^{2}$ Faculty of Engineering, Universiti Putra Malaysia, 43400 Serdang Selangor D.E, Malaysia
}

\begin{abstract}
The tractive performance justification of an off-road vehicle is so important that it ensures the vehicle mobility over the unprepared peat terrain. Tractive performance of Low Ground Pressure (LGP-30) wheeled vehicle is investigated on the low bearing capacity moderate peat terrain in Malaysia. The simulation results showed that the vehicle sinkage is more than the critical sinkage value of $100 \mathrm{~mm}$, ground contact pressure is more than $17 \mathrm{kN} / \mathrm{m}^{2}$, and rolling motion resistance due to terrain compaction is very often more than the tractive effort of the vehicle. The vehicle was tested on the unprepared moderate peat terrain after increasing the tyre-terrain interface by decreasing the tyre inflation pressure of $5 \%$, $10 \%$ and $15 \%$ respectively. The vehicle was found to traverse on the terrain smoothly when the tyre inflation pressure was decreased by $15 \%$.
\end{abstract}

Keywords: Peat terrain, kinematics model, LGP-30 wheeled vehicle, tractive performance.

\section{INTRODUCTION}

Typical peat characteristics as found in Malaysia are the presence of submerged and un-decomposed woods, stumps and logs. These submerged and unrecompensed logs or stumps impede the movement of machinery in the field. Other important characteristics are the very high ground water table, low bulk density and bearing capacity. Under the loaded surface some of peat soil may be at rest while others may move down. It is very difficult to manage any vehicle operation on peat terrain to do the transportation of palm oil fresh fruit bunches and other goods. This study investigates the LGP-30 wheeled vehicle tractive performance investigates through theoretically and experimentally. The major purpose of this study is to justify the LGP-30 wheeled vehicle suitability over the moderate peat terrain in Malaysia.

\section{MATHEMATICAL MODEL FOR WHEELED VE- HICLE}

The LGP-30 wheeled vehicle suitability in terms of its tractive performance is analysed by taking account of the vehicle's weight, ground pressure distribution, sinkage, slippage, and center of gravity of the location. Other parameters include the ground contact area and vehicle ground clearance. The development of the mathematical model in this study is initiated by classifying into two groups: (i) a kinematics model of rolling wheel is developed based on the slippage of the vehicle with consideration of the rolling of a single tire as a cycloid, and (ii) the algorithms modeling for the tyre-terrain interaction mechanism by simplifying the general tractive equations and motion resistances equations reported in references [1-6].

*Address correspondence to this author at the Department of Mechanical Engineering (Mechanical-Automotive Engineering), Faculty of Engineering, International Islamic University Malaysia (IIUM), 50728 Kuala Lumpur, Malaysia; Tel: +6-03-61964544; E-mail: arat@iiu.edu.my
The motion of the vehicle's rolling wheel relative to the terrain is determined by analyzing the kinematics of the wheel. While the tangential force (tractive force) is determined based on the tyre-terrain interaction mechanism which could be achieved by reducing the inflation pressure of the tyre.. The basic concept to determine the vehicle's ground contact pressure distribution is to understand the vehicle's mobility over the low bearing capacity peat terrain. On a peat terrain, the performance of the vehicle is, to a great extent, dependent upon the manner in which the vehicle interacts with the terrain.

The following assumptions are made to validate the mathematical model for wheeled vehicle:

- $\quad$ Based on the study of peat terrain mechanical properties addressed in ref. [7], the vehicle critical slip sinkage and ground contact pressure are considered to be $100 \mathrm{~mm}$ and $17 \mathrm{kN} / \mathrm{m}^{2}$, respectively.

- $\quad$ Terrain reaction at all points on the contact patch is purely radial and is equal to the normal pressure beneath a horizontal contact area of the vehicle.

- The perimeter of the tire contact area and the velocity of the vehicle are considered to be constant.

- The rotational inertia of the vehicle rotating parts is neglected as it has no significant effect on the vehicle performance for straight motion.

\subsection{Ground Contact Pressure}

The vehicle's mobility is limited by the terrain capacity. In general, if the vehicle ground contact pressure is more than the normal ground pressure of the terrain, the vehicle is at risk to operate on the low bearing capacity peat terrain. In order to increase the floatation capacity of the vehicle and decrease the vehicle ground contact pressure on the tire- 
terrain interface, the tire inflation pressure is assumed to be reduced. Therefore, a portion of the circumference of the tire will be flattened. The total pressure of the tire, $P_{0}$ on the peat terrain will be the sum of the inflation pressure $P_{i}$ and the pressure due to carcass stiffness $P_{c}$. Based on the characteristics of low bearing capacity peat terrain, a vehicle would not potentially be able to traverse on the peat terrain if the ground contact pressure of the vehicle is greater than the normal ground pressure of the terrain i.e., $P_{i}+P_{c}=P_{g} \leq P_{v c}$. The normal ground pressure of the terrain is determined by the following equations recommended in ref. [3]:

$$
P_{g}=\left(k_{p} z_{o}+\frac{4}{D_{h}} m_{m} z_{0}^{2}\right)
$$

where $D_{h}=\frac{B H}{(H+B)}$

In Equation (1), $P_{g}$ is the normal ground pressure in $\mathrm{kN} / \mathrm{m}^{2}$ and $z_{o}$ the critical sinkage (i.e., rut of depth or surface mat thickness) in $\mathrm{m}, m_{m}$ the surface mat stiffness in $\mathrm{kN} / \mathrm{m}^{3}$, $k_{p}$ the underlying peat stiffness in $\mathrm{kN} / \mathrm{m}^{3}$, and $D_{h}$ the hydraulic diameter in $\mathrm{m}$, while $B$ and $H$ are the width and ground contact length of the wheel in $\mathrm{m}$, respectively. The critical sinkage of the vehicle in this study is defined as the surface mat thickness of the peat terrain which is considered the allowable sinakge of the vehicle. It is anticipated that if the critical sinkage of the vehicle is more than the allowable sinkage, the vehicle will be highly at risk to traverse and it would be immobalised as the slippage increases.

\subsection{Sinkage}

Sinkage of vehicle causes the power and traction loss. The vehicle performance is severely affected on the vehicle tractive performance if the sinkage of the vehicle is more than or equals to vehicle critical sinkage. The amount of sinkage of the vehicle can be computed by using the following equation recommended in ref. [8]:

$z_{0}=\frac{-\left(\frac{k_{p} D_{h}}{4 m_{m}}\right) \pm \sqrt{\left[\left(\frac{k_{p} D_{h}}{4 m_{m}}\right)^{2}+\frac{D_{h}}{m_{m}} P_{v c}\right]}}{2}$
In the Equation (2), $P_{v c}$ is the ground contact pressure of the vehicle in $\mathrm{kN} / \mathrm{m}^{2}$. If the vehicle ground contact pressure $P_{v c}$ is greater than the ground normal pressure $P_{g}$, the critical sinkage $z_{o}$ would be more than the surface mat thickness $z_{m}$ (i.e, $z_{o}>z_{m}$ ).

\subsection{Slippage}

Slip is one of the functional parameters for the vehicle traction mechanism. As the tractive force developed by a tire is proportional to the applied wheel torque under steady state conditions, slip is a function of tractive effort. It could be supported by the Eq.32. The slip is defined as the ratio of the linear velocity at the tire centre to the spin velocity of straight free-rolling tire expressed as a percentage. If the vehicle remains stuck and wheel slip continues, the driving force is reduced drastically. The slip of the wheel could determine by using the cycloid principle. A cycloid is the curve defined by a fixed point on a rim of the wheel as it rolls, or, more precisely, the locus of a point on the rim of a circle rolling along a straight line. Points of rolling rim describe a cycloid. Consider a wheel of radius $R_{0}$ which is free to roll along the $\mathrm{x}$-axis. As the wheel turns, a point $\mathrm{P}$ on the tire traces out a curve. Assume $\mathrm{P}$ is initially at the origin and let $\mathrm{C}$ and $\mathrm{T}$ are located as indicated in Fig. (1), with $\phi$ denoting the radian measure of angle TCP. Then the arc PT and the segment OT have the same length such that the center $\mathrm{C}$ of the rolling circle is at $\left(\mathrm{R}_{0} \phi, \mathrm{R}_{0}\right)$. Using trigonometry, it could be concluded that

$$
\begin{aligned}
& x=R_{0} \varphi-R_{0} \sin \varphi=R_{0}(\varphi-\sin \varphi) \\
& y=R_{0}-R_{0} \cos \varphi=R_{0}(1-\cos \varphi)
\end{aligned}
$$

Fig. (2) shows a wheel of the vehicle rolls on peat terrain with load and the displacement of the contact point of the wheel relative to the peat terrain. Individual points of the wheel perimeter move along looped cycloid.

$$
x=U-H / 2
$$

where $U=R_{1} \sin \varphi_{1}+R_{1} \sin \varphi_{2}$ and $\varphi=\varphi_{1}+\varphi_{2}$

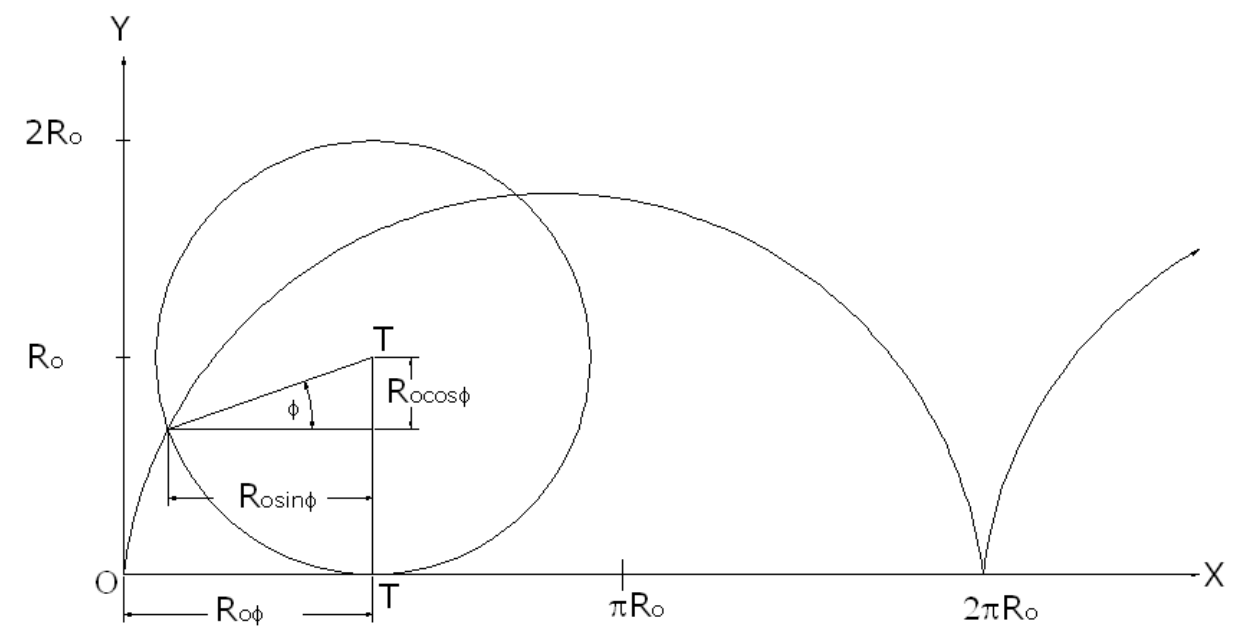

Fig. (1). Typical cycloid for the wheeled vehicle rolling on peat terrain. 


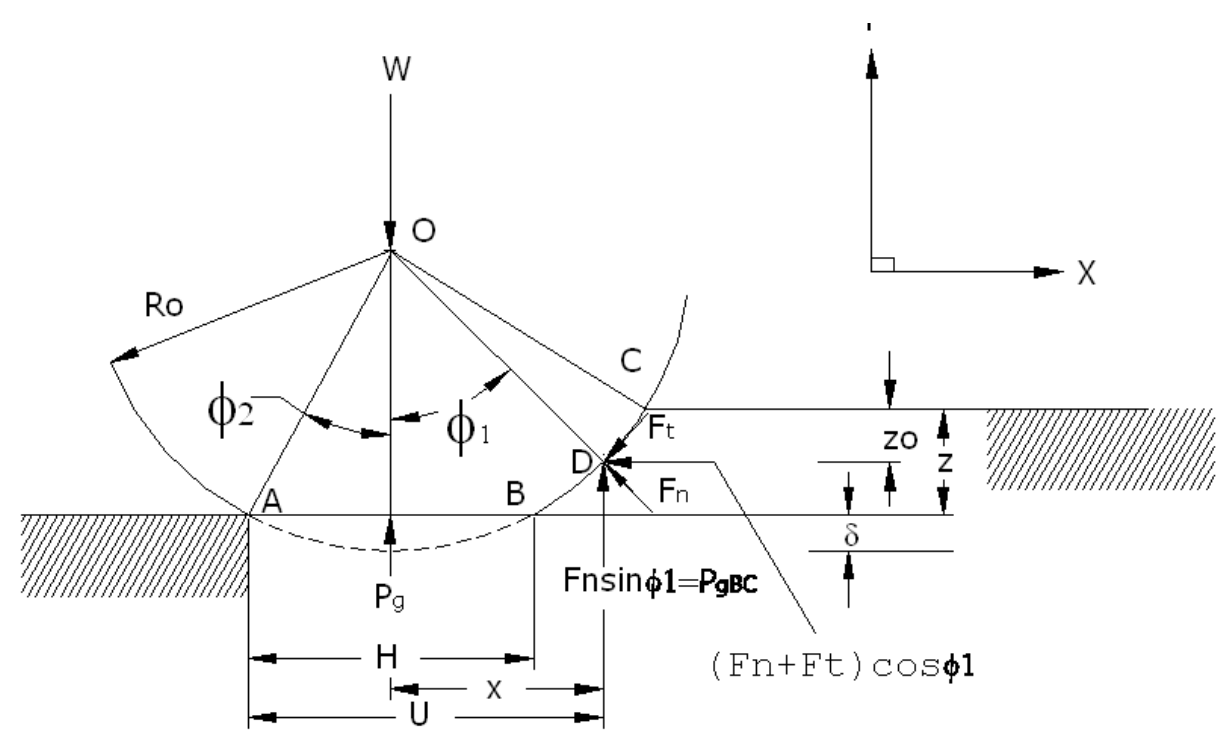

Fig. (2). Points on the perimeter of a driving wheel describe a looped cycloid.

In Equation (5), $R_{1}$ is radius of the point on the perimeter, which is being examined, $U$ the length of the contact surface or the horizontal projection of the contact arc, and $\phi$ the central angle which belongs to $\mathrm{U}$.

It is assumed that the driving wheels operate with exerting tangential force (tractive force) due to the applying driving torque at the wheel, and its vertical deformation and the accompanying soil deformations create a condition as if the wheels roll with slip with radius $R_{z}$. The radius $R_{z}$ can be measured by using the following equation:

$R_{z}=R_{0}\left(1-i_{r d}\right)$

where, $i_{r d}=\left(1-\frac{V}{R_{o} \omega}\right) \times 100 \%=\left(1-\frac{R_{z}}{R_{o}}\right) \times 100 \%$

In Equation (6), $i_{r d}$ is the slippage of wheel relative to the terrain in percentage which is induced due to the friction at the interface between driving wheel and terrain, $V$ is the linear speed at the tire wheel in $\mathrm{m} / \mathrm{s}$, and $\omega$ is the angular speed of the tire in rad./s.. The resulting slip radius $R_{i}$ can be calculated by using the following equation:

$R_{i}=R_{z} \cdot(1-i)=R_{0} \cdot\left(1-i_{r d}\right)(1-i)=R_{0}\left(1-i_{r}\right)$

In Equation (7), $i_{r}$ is the resultant slippage, $i_{r}=i+i_{r d}$ and $i . i_{r d} \cong 0$.

with $i_{r}=\left(1-\frac{V}{R_{i} \omega}\right) \times 100 \%$

When the driving wheel is under slippage, the displacement of the vehicle due to the slippage (i.e., slip displacement) of the wheel can be represented by rewriting the Equation (7):

$x=U-H / 2=R_{i} \varphi-H / 2=R_{0} \varphi\left(1-i_{r}\right)-H / 2$

The resultant slippage, $i_{r}$ is caused by the tangential force and tire deformation. Equation (8) represents slip displace- ment when considering the kinematics interaction at the tireterrain interface.

When the deformable tire rolls with radius $\mathrm{R}_{0}$, the resultant slippage is zero, or $i_{r}=0$. The displacement of the tire can be written as

$x_{0}=R_{0} \varphi-H / 2$

In Equation (9), $\mathrm{x}_{0}$ is the displacement of the tire when $i_{r}=o$

When $i=0$, the slip displacement of the tire will be zero ( $x=0)$, and Equation (8) can be rewritten as

$$
\begin{aligned}
& x=R_{0} \varphi\left(1-i_{r d}\right)-H / 2=0 \\
& i_{r d}=i_{r}=1-\frac{H}{\left(2 R_{0} \varphi\right)}=\left(1-\frac{V}{R_{z} \omega}\right) \times 100 \% \\
& =\left(1-\frac{V}{R_{i} \omega}\right) \times 100 \%
\end{aligned}
$$

In this study it is assumed that the vehicle ground contact pressure is higher than the normal ground pressure i.e., $P_{v c}>P_{g}$, the tire operates in elastic mode, and the lower part of the tire in contact with the terrain is flattened. The inflation pressure of the tire is reduced; it is assumed that the deflection of the tire will be $\delta$. The contact length of the tire $\mathrm{H}$ can be computed by considering the vertical equilibrium of the tire. The length of the contact surface is definitely the function of the tire deflection. Therefore, $\mathrm{H}$ is computed by considering the tire deflection $\delta$,

$$
H=2 \sqrt{[(\delta)(D-\delta)]}=\left(2 R_{o} \varphi\right)\left(1-\left(1-\frac{V}{R_{i} \omega}\right) \times 100 \%\right)
$$

where, $\mathrm{D}$ is the diameter of the tire in meter. 
In Fig. (2), the point ' $\mathrm{D}$ ' is the normal force acting point on the curve $\mathrm{BC}$ of the wheel and ' $\mathrm{z}$ ' is defined as the depth of the normal force acting point (i.e., $z=\oint($ Position of $D)$. The slip sinkage of the vehicle is computed in this study by using $z^{\prime}=z_{o}-z$. The slip sinkage is defined as the sinkage of the vehicle due to the slippage. It is earlier mentioned that the slippage of the vehicle increases with stucking the vehicle. If the slip sinkage of the vehicle equals to zero (i.e., $z^{\prime}=0$ ), the point ' $\mathrm{D}$ ' would be at the point $\mathrm{B}$. While, the point ' $\mathrm{D}$ ' would be at the middle of curve $\mathrm{BC}$ if $z=\frac{1}{2} z_{o}$.

Therefore, the entry angle $\phi_{1}$ and exit angle $\phi_{2}$ invoked during forward traveling on the terrain, may be computed as:

$\varphi_{1}=\sin ^{-1}\left(\frac{2 x}{D}\right)$

$\varphi_{2}=\sin ^{-1}\left(\frac{H}{2 D}\right)$

$\varphi=\sin ^{-1}\left(\frac{2 x}{D}\right)+\sin ^{-1}\left(\frac{H}{2 D}\right)$

It can be further written based upon the geometry shown in Fig. (3):

$$
x=\sqrt{\left\{D\left(z_{0}+\delta-z\right)\right\}-\left(z_{0}+\delta-z\right)^{2}}
$$

or

$$
x=\sqrt{\left\{\left(z_{0}+\delta-z\right)\left(D-\left(z_{0}+\delta-z\right)\right)\right\}}
$$

The assumption for the stress distribution addressed in ref. [6] that the motion resistance of a rigid wheel is due to the vertical work done in making a rut of depth $\mathrm{z}_{0}$. The force
$\mathrm{F}_{\mathrm{n}}$ acts as the normal force on the curve $\mathrm{BC}$ as point $\mathrm{D}$ of the wheel's tangential force $\mathrm{F}_{\mathrm{t}}$, leading to following equations:

- If the slip sinkage, $z \cong^{z_{0}} / 2$

$$
x=\sqrt{\left\{\left(z_{0} / 2+\delta\right)\left(D-z_{0} / 2-\delta\right)\right\}}
$$

- If slip sinkage, $z \cong z_{0}$

$$
x=\sqrt{[(\delta)(D-\delta)]}
$$

The total entry and exit angle $\phi$ of the tire can be computed by simplifying Equations (16) and (17) as shown in the follows:

- For slip sinkage, $z \cong z_{0} / 2$
$\varphi=\sin ^{-1}\left(\frac{2 \sqrt{\left\{\left(z_{0} / 2+\delta\right)\left(D-z_{0} / 2-\delta\right)\right\}}}{D}\right)+\sin ^{-1}(H / 2 D)$

- $\quad$ For slip sinkage, $z \cong z_{0}$

$$
\varphi=\sin ^{-1}\left(\frac{2 \sqrt{\{\delta(D-\delta)\}}}{D}\right)+\sin ^{-1}(H / 2 D)
$$

The slippage of the vehicle can be computed by combining Equations (10), (19) and (20) as shown below.

- $\quad$ For slip sinkage, $z \cong z_{0} / 2$

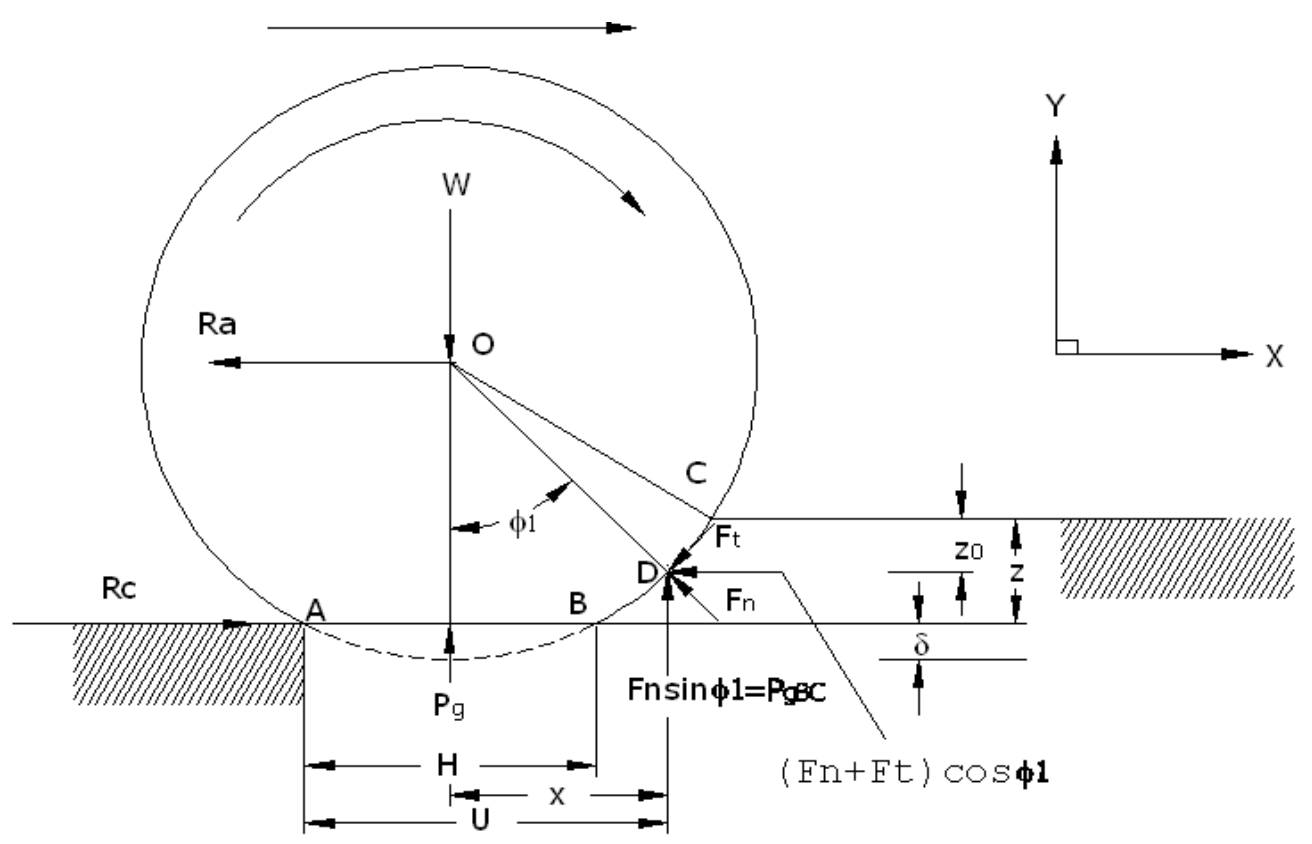

Fig. (3). Wheel-terrain interaction model. 


$$
i_{r d}=1-\frac{2 \sqrt{\{\delta(D-\delta)\}}}{\sin ^{-1}\left\{\frac{2 \sqrt{\left\{\left(z_{0} / 2+\delta\right)\left(D-z_{0} / 2-\delta\right)\right\}}}{D}\right\}}\left[\begin{array}{l}
+\sin ^{-1}\left(\frac{2 \sqrt{[\delta(D-\delta)]}}{D}\right)
\end{array}\right]
$$

- For slip sinkage, $z \cong z_{0}$

$$
i_{r d}=1-\frac{2 \sqrt{\{\delta(D-\delta)\}}}{2 R_{0}\left[\begin{array}{l}
\sin ^{-1}\left\{\frac{2 \sqrt{\{\delta(D-\delta)\}}}{D}\right\} \\
+\sin ^{-1}\left(\frac{2 \sqrt{\{\delta(D-\delta)\}}}{D}\right)
\end{array}\right]}
$$

In practice, it would be more convenient to follow an iterative process to determine the values of $\delta, H$ and $\varphi$ by using the Equations (11), (20), and (21) with assuming the values of $i_{r d}$ in the range of 10-100\%. Finally, the values of $i_{r d}$ could be verified by the computing values of $\mathrm{H}$ and $\varphi$.

\subsection{Load Distribution}

The normal load $\mathrm{W}$ is supported by the normal ground pressure $\mathrm{P}_{\mathrm{g}}$ on the tire flattened portion $\mathrm{AB}$ and arc portion $\mathrm{BC}$. Therefore, part of the tire load will be supported by the portion of the curve $\mathrm{BC}$ as shown in Fig. (3). The vehicle load on the curve BC due to the effect of the vertical component of the wheel tangential force $F_{t} \sin \phi_{1}$ is considered to be $\mathrm{W}_{\mathrm{BC}}$ and it could be computed as follows:

$$
\begin{aligned}
W_{B C} & =B \int_{0}^{z 0} P_{g} d x \\
W_{B C} & =B \int_{0}^{z_{0}}\left(k_{p} z+\frac{4}{D_{h}} m_{m} z^{2}\right) d x
\end{aligned}
$$

The computation of the vehicle load distribution could be made for minimum slip sinkage to critical sinkage. For the minimum slip sinkage of the vehicle $\mathrm{W}_{\mathrm{BC}}$ could be made by differentiating the Equation (15) with neglecting the secondary term and we have,

$$
d x=\frac{-D d z}{2 \sqrt{\left\{D\left(z_{0}+\delta-z\right)\right\}}}
$$

Substituting $d x$ in Equation (22) leads to:

$$
W_{B C}=\int_{0}^{z_{0}} \frac{B \sqrt{D}}{2 \sqrt{\left(z_{0}+\delta-z\right)}}\left(k_{p} z+4 m_{m} \frac{(H+B)}{(H B)} z^{2}\right) d z
$$

Assuming $\left(z_{0}+\delta-z\right)=p^{2}$, results in $d z=-2 p d p$, Equation (23) can be rewritten as
$W_{B C}=\int_{\sqrt{\left(z_{0}+\delta\right)}}^{\sqrt{z}} B\left(k_{p} z+4 m_{m} \frac{(H+B)}{H B} z^{2}\right)(\sqrt{-D}) d p$

By using, $z=\left(z_{0}+\delta-p^{2}\right)$ in Equation (23), we have,

$$
\begin{aligned}
& W_{B C}=-B k_{p} \sqrt{D} \int_{\sqrt{\left(z_{0}+\delta\right)}}^{\sqrt{\delta}}\left(z_{0}+\delta-p^{2}\right) \\
& d p-\frac{(H+B)}{H B}\left(4 m_{m}\right) \sqrt{D} \int_{\sqrt{\left(z_{0}+\delta\right)}}^{\sqrt{\delta}}\left(z_{0}+\delta-p^{2}\right)^{2} d p
\end{aligned}
$$

It is considered that the vehicle load will be supported by the underlying peat stiffness $k_{p}$ if the vehicle sinkage is more than the surface mat thickness of 0.12 to $0.7 \mathrm{~m}$. This study focuses on the effect of vehicle sinkage, $z \leq 0.10 \mathrm{~m}$ and the maximum slip sinkage (i.e., $z \cong z_{0}$ ). Thus the equation (26) can be rewritten as follows:

$W_{B C}=-B k_{p} \sqrt{D} \int_{\sqrt{\left(z_{0}+\delta\right)}}^{\sqrt{z}}\left(z_{0}+\delta-p^{2}\right) d p$

By simplifying equation (26), we can write

$W_{B C}=B k_{p} \sqrt{D}\left[\frac{2}{3} \delta^{1 / 2}\left(\delta+1.5 z_{0}\right)-\frac{2}{3}\left(\delta+z_{0}\right)^{2 / 3}\right]$

The vertical force applied on the tire can be expressed as

$W=B H p_{g}+W_{B C}$

The traction mechanics of the tire-terrain interfaces can be calculated by using the following equation recommended in ref. [6]:

$F_{T}=2 B \int_{0}^{L} \tau d x$

where $\tau=\tau_{\max }\left(\frac{j_{x}}{K_{w}}\right) \exp \left(1-\frac{j_{x}}{K_{w}}\right), \tau_{\max }=(c+\sigma \tan \phi)$, and $j_{x}=i x$

From the wheel-terrain interaction model as shown in Fig. (3), the tractive force of the vehicle could be determined by applying the Newton's motion law:

$$
\begin{aligned}
& \left(F_{t}+F_{n}\right) \sin \phi_{1}-R_{c}-R_{a}=\frac{W}{g} \frac{d}{d t}(v) \\
& \left(F_{t}+F_{n}\right) \sin \phi=R_{c}+R_{a}+\frac{W}{g} \frac{d}{d t}(v)
\end{aligned}
$$

where, $\left(F_{t}+F_{n}\right) \sin \phi=2 B \int_{0}^{L} \tau d x$ and $F_{t}+F_{n}=F$

In equation (30), $\mathrm{F}_{\mathrm{t}}$ is the tangential force in $\mathrm{kN}, \mathrm{F}_{\mathrm{n}}$ is the normal force that exert from the terrain in $\mathrm{kN}, \mathrm{W}$ is the total of the vehicle weight in $\mathrm{kN}, \mathrm{R}_{\mathrm{c}}$ is the motion resistance due to terrain compaction in $\mathrm{kN}$ and $v$ is the traveling speed of the vehicle in $\mathrm{km} / \mathrm{h}$. 
By integrating Equation (30), the tractive effort equation of the tire-terrain interfaces can be written as

$$
\begin{aligned}
& F=\frac{1}{\left(\sin \phi_{1}\right)} A_{t}(c+\sigma \tan \phi)\left[\frac{K_{w}}{i L_{t}} e^{1}-\left(1+\frac{K_{w}}{i L_{t}}\right) \exp \left(1-\frac{i L_{t}}{K_{w}}\right)\right](31) \\
& \text { where } \sigma=\frac{W}{A_{t}} \text { and } A_{t}=B L_{t}=B\left(H+x-\frac{H}{2}\right)=B\left(\frac{H}{2}+x\right)
\end{aligned}
$$

In Equation (31), $\sigma$ is the normal stress of the vehicle on the tire-terrain interaction in $\mathrm{kN} / \mathrm{m}^{2}, i$ the slippage in percentage, and $K_{w}$ the shear deformation modulus in $\mathrm{m}$.

\subsection{Motion Resistance}

Motion resistance is an important parameter to evaluate the tractive performance of the designed tracked vehicle on peat terrain. Since the peat is defined as the combination of decomposed materials, the external motion resistance of the vehicle is not incurred due to terrain compaction but also due to the bull dozing effect. Bekker mentioned that if the sinkage of the tire is significant the bull dozing effect should be taken into account in the calculation of the total motion resistance. The motion resistance resulted from terrain compaction can be represented by simplifying the general equation with the pressure sinkage equation recommended in ref. [3]:

$$
R_{c} L=2 B L \int_{0}^{z 0} p_{g} d z
$$

where $p_{g}=\left(k_{p} z+\frac{4}{D_{h}} m_{m} z^{2}\right)$

By integrating Equation (32), the motion resistance due to terrain compaction can be derived as,

$$
R_{c}=2 B\left(\frac{k_{P} z_{0}^{2}}{2}+\frac{4}{3 D_{h}} m_{m} z_{0}^{3}\right)
$$

In Equation (33), $R_{c}$ is the motion resistance due to terrain compaction in $\mathrm{kN}$.

The motion resistance due to bull dozing effect was determined by using the general equation recommended in ref. [3]:

$$
R_{b}=2 B\left[\gamma_{d} z_{0}^{2} \tan ^{2}\left(45+\frac{\phi}{2}\right)+c z_{0} \tan \left(45+\frac{\phi}{2}\right)\right]
$$

In Equation (34), $R_{b}$ is the motion resistance due to bull dozing effect for the rear sprocket in $\mathrm{kN}, \varphi$ the internal frictional angle of the peat terrain in degree, $c$ the cohesiveness in $\mathrm{kN} / \mathrm{m}^{2}, z_{0}$ the critical sinkage in $\mathrm{cm}, B$ the track width in $\mathrm{m}$, and $\gamma_{d}$ the bulk density of the peat soil in $\mathrm{kN} / \mathrm{m}^{3}$.

The motion resistance due to tire deformation can be computed by using the equation recommended in ref. [4]:

$$
R_{h}=\frac{\left[3.58 B D^{2} P_{g} \varepsilon(0.035 \alpha-\sin 2 \alpha)\right]}{\alpha(D-2 \delta)}
$$

where $\alpha=\cos ^{-1}\left[\frac{(D-2 \delta)}{D}\right]$ and $\varepsilon=1-\exp \left(-k_{e} \delta / h\right)$

In Equation (35), $\alpha$ is the contact angle in degrees, $h$ the tire section height in $\mathrm{m}$, and $k_{e}$ a parameter related to tire construction. The values of $k_{e}$ is 7 for radial tire and 15 for bias-ply tires addressed in ref. [1].

\section{TRACTIVE PERFORMANCE INVESTIGATION}

Vehicle tractive performance in terms of tractive effort and slippages was investigated by simulation and conducting the field experiment. The comparison on the simulation and the field experimental results has been made to substantiate the validity of the developed mathematical model in this study.

\subsection{Simulation Results}

The suitability of the vehicle as shown in Fig. (4) is justified with its tractive performance simulation by considering the peat terrain mechanical properties such as moisture content $\omega$, bulk density $\gamma$, cohesiveness c, internal friction angle $\varphi$, shear deformation modulus $K_{W}$, surface mat stiffness $m_{m}$, and underlying peat stiffness $k_{p}$ as stated in Table $\mathbf{1}$. The specifications of the LGP-30 vehicle are shown in Table 2. The main drive ratio of this vehicle power transmission system is $1: 1$. For the simulation of the vehicle LGP-30 on Sepang peat terrain, the vehicle travelling distance is considered to be $200 \mathrm{~m}$, the terrain mean surface mat thickness and underlying peat thickness were considered $0.12 \mathrm{~m}$ and $3 \mathrm{~m}$, respectively.

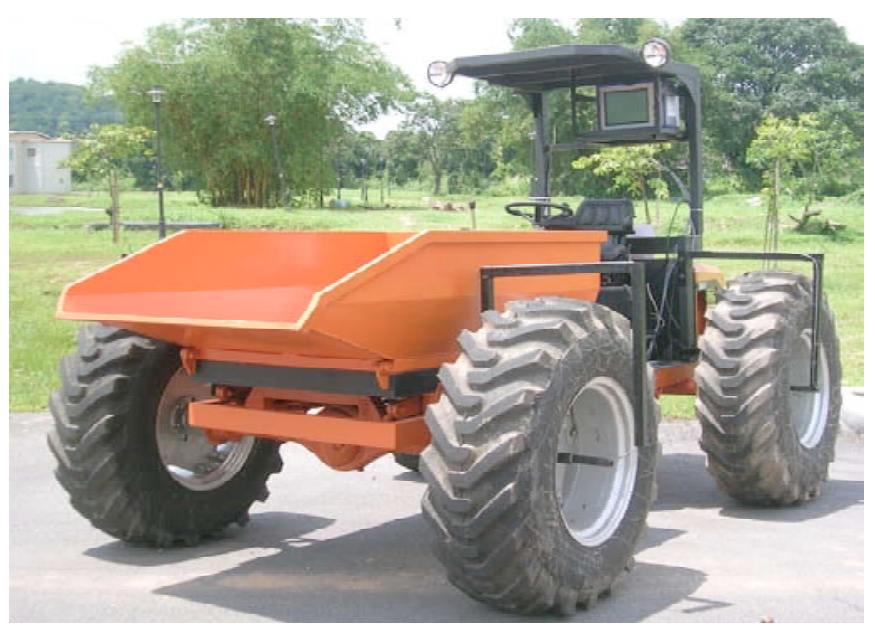

Fig. (4). LGP-30 instrumented wheeled vehicle.

Table 1. Peat Terrain Parameters

\begin{tabular}{|c|c|c|c|c|}
\hline \multirow{2}{*}{ Parameters } & \multicolumn{2}{|c|}{ Un-Drained } & \multicolumn{2}{c|}{ Drained } \\
\cline { 2 - 5 } & Mean Value & SD & Mean Value & SD \\
\hline \hline$\omega,(\%)$ & 83.51 & - & 79.58 & - \\
\hline$\gamma,\left(\mathrm{g} / \mathrm{cm}^{3}\right)$ & 0.156 & 0.06 & 0.186 & 0.08 \\
\hline$\left.c, \mathrm{kN} / \mathrm{m}^{2}\right)$ & 1.36 & 0.21 & 2.73 & 0.39 \\
\hline$\varphi,(\mathrm{degree})$ & 23.78 & 4.56 & 27.22 & 2.19 \\
\hline$K_{w},(\mathrm{~cm})$ & 1.19 & 0.10 & 1.12 & 0.17 \\
\hline$m_{\mathrm{m}},\left(\mathrm{kN} / \mathrm{m}^{3}\right)$ & 27.07 & 13.47 & 41.79 & 13.37 \\
\hline$k_{p},\left(\mathrm{kN} / \mathrm{m}^{3}\right)$ & 224.38 & 52.84 & 356.8 & 74.27 \\
\hline
\end{tabular}


Table 2. LGP-30's Specifications

\begin{tabular}{|c|c|c|}
\hline \multicolumn{3}{|l|}{ Vehicle Parameters } \\
\hline Engine power@ @rpm,kW & $\mathrm{E}_{\mathrm{p}}$ & 40@3300 \\
\hline Maximum net torque, $\mathrm{N}-\mathrm{m}$ & $\mathrm{Q}_{\mathrm{n}}$ & 775.74 \\
\hline Overall length, $\mathrm{m}$ & $\mathrm{L}$ & 4.51 \\
\hline Overall width, m & $B_{v}$ & 2.17 \\
\hline Overall height, $\mathrm{m}$ & $\mathrm{H}$ & 1.74 \\
\hline Weight, $\mathrm{kg}$ & W & 2650 \\
\hline Load carrying capacity, $\mathrm{kg}$ & $\mathrm{W}_{\mathrm{p}}$ & 1000 \\
\hline Full operating weight, $\mathrm{kg}$ & $\mathrm{W}_{\mathrm{o}}$ & 1600 \\
\hline Tire & \multicolumn{2}{|c|}{ 16.9X24 8PR Tube Type } \\
\hline Ground clearance, $\mathrm{m}$ & $\mathrm{G}_{\mathrm{c}}$ & 0.48 \\
\hline Wheel diameter, $\mathrm{m}$ & $\mathrm{D}$ & 121.38 \\
\hline Wheel base, $\mathrm{m}$ & $\mathrm{L}_{\mathrm{w}}$ & 2.39 \\
\hline
\end{tabular}

The critical sinkage of the vehicle is considered to be $0.120 \mathrm{~m}$ as the surface mat thickness was found $0.12 \mathrm{~m}$ from the earlier study reported in ref. [8]. The field experiment for getting the mechanical properties of Sepang peat has been conducted in 15 different points over the $200 \mathrm{~m}$ traveling path of the vehicle and the same experimental methods has been repeated 5 times over the $200 \mathrm{~m}$. The simulation on the LGP-30 vehicle is made on the vehicle sinkage, pressure, slippage, tractive effort (traction), and motion resistance by considering the mechanical properties of the terrain for the 15 different points over the $200 \mathrm{~m}$ vehicle traveling path.

The sinkage and the tractive equation are quite similar to those recommended in ref. [9]. The kinematics model in this study is validated with the field experimental results addressed in ref. [9]. It is noted that if the vehicle wheel sinkage is less than $100 \mathrm{~mm}$ the vehicle will be supported by both the surface mat and the underlying peat. But, if the vehicle sinkage is $120 \mathrm{~mm}$ or more the vehicle is in risk because the vehicle is supported only by the strength of the underlying peat.

Fig. (5) shows the typical sinkage of the LGP-30 vehicle on the Sepang peat terrain, showing the minimum sinkage of $0.24 \mathrm{~m}$ and $0.28 \mathrm{~m}$ for the $26 \mathrm{kN}$ and $34.5 \mathrm{kN}$ LGP-30 vehicle, respectively. As mentioned previously, most of the vehicle load is supported by the surface mat of the peat terrain, but in the case when the vehicle minimum sinkage is $0.24 \mathrm{~m}$ for the vehicle of $24 \mathrm{kN}$, the load of the vehicle would be supported by the underlying peat only. Furthermore, when the ground clearance of the vehicle is $0.48 \mathrm{~m}$, the vehicle is completely in risk to traverse on the peat terrain unless some modifications are adopted in order to make the vehicle sinkage less than $0.10 \mathrm{~m}$.

Fig. (6) shows that the slippage of the vehicle increases with the increase in vehicle load. Fig. (7) shows that the vehicle's sinkage and slippage as a function of travel distance. It is noted that the sinkage of the vehicle increases with the increase in vehicle slippage. It could be concluded that the vehicle sinkage is a function of vehicle slippage. Equation 20

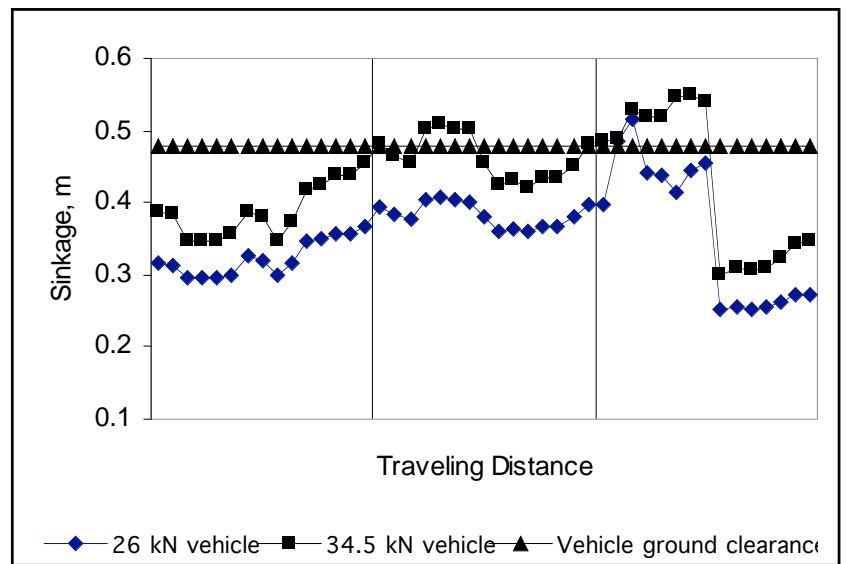

Fig. (5). Typical sinkage of the LGP-30 wheeled vehicle on Sepang peat terrain.

represents the same relationship as the relationship of the sinkage and slippage in Fig. (7). Furthermore, it should be mentioned that if the vehicle slippage increases too much the vehicle will spin rather than rolling, which is the major cause of the vehicle sinkage. This study indicates that the vehicle sinkage for the LGP-30 wheeled vehicle should not be more than $0.48 \mathrm{~m}$ as the vehicle ground clearance is $0.48 \mathrm{~m}$ and the maximum slippage should not be more than $40 \%$ in order to allow the LGP-30 vehicle to move.

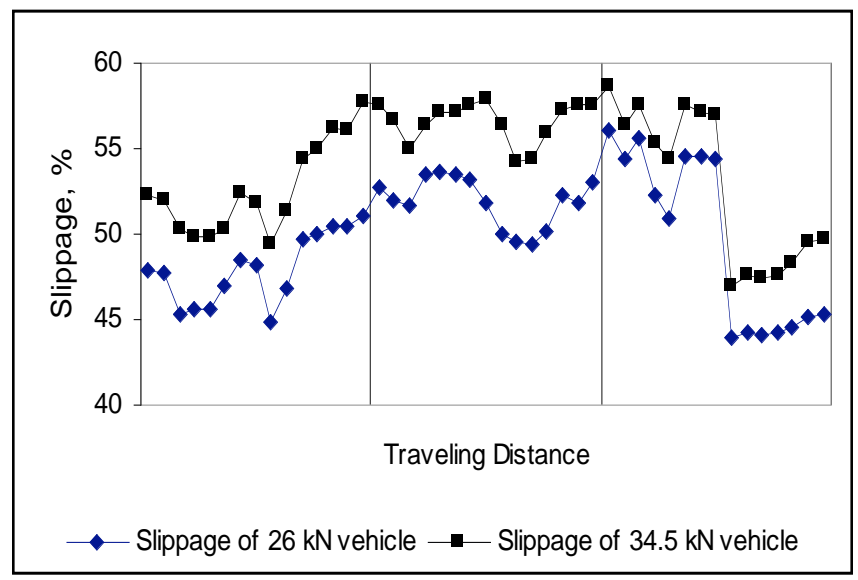

Fig. (6). Typical slippage of the LGP-30 wheeled vehicle on Sepang peat terrain.

The mobility of off-road vehicles is justified based on the relationship between vehicle ground contact pressure and ground normal pressure distribution, especially for peat or muskeg terrain. If the ground contact pressure of the vehicle is higher than the vehicle ground normal pressure, the vehicle would not be able to traverse on the terrain rather to sink. Based on Fig. (8), it could be concluded that the vehicle LGP-30 would not be able to mobile on the terrain as the vehicle normal ground pressure is much higher than the vehicle ground normal pressure. Fig. (9) shows the vehicle tractive force for the slippage of $20 \%, 30 \%$ and $40 \%$. Based on this it could be concluded that the vehicle traction decreases with increasing slippage of the vehicle and the vehicle tractive force increases with increasing the vehicle weight. Fig. (10) shows that the maximum tractive force $44.23,34.62$, and $23.85 \%$ of the vehicle weight $34.5 \mathrm{kN}$ for 
(a) LGP-30, vehicle weight $=26 \mathrm{kN}$

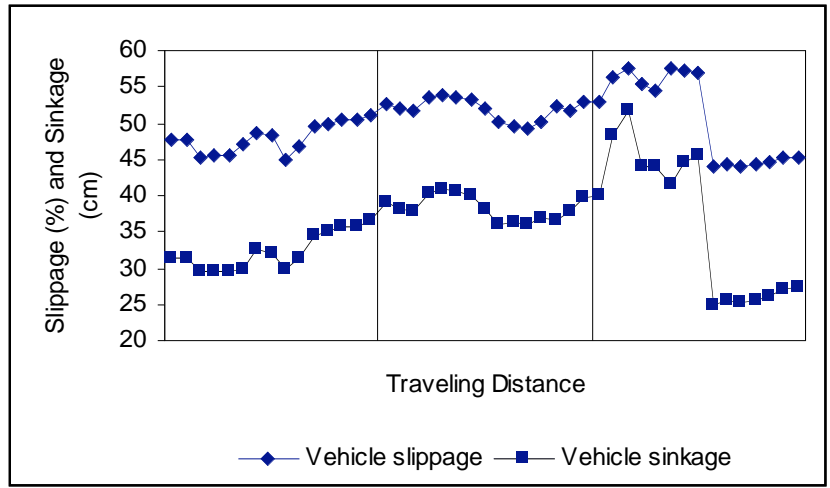

(b) LGP-30, vehicle weight $=34.5 \mathrm{kN}$

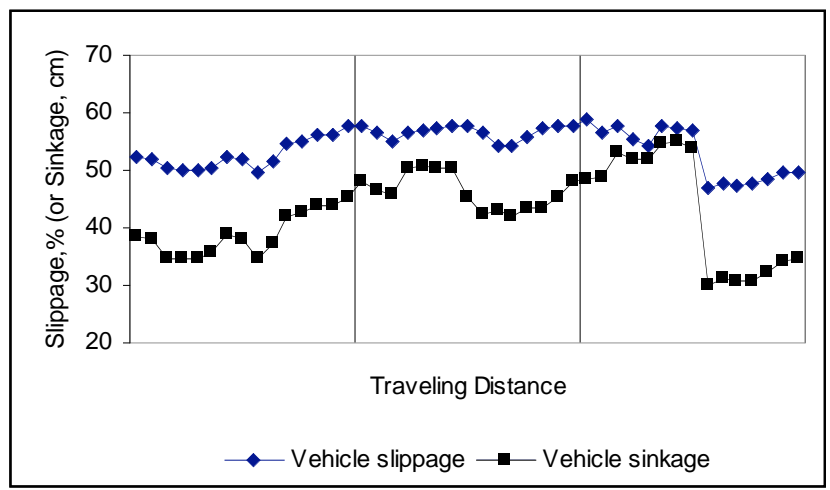

Fig. (7). Relationship between vehicle slippage and sinkage.

(a) LGP-30, vehicle weight $=26 \mathrm{kN}$

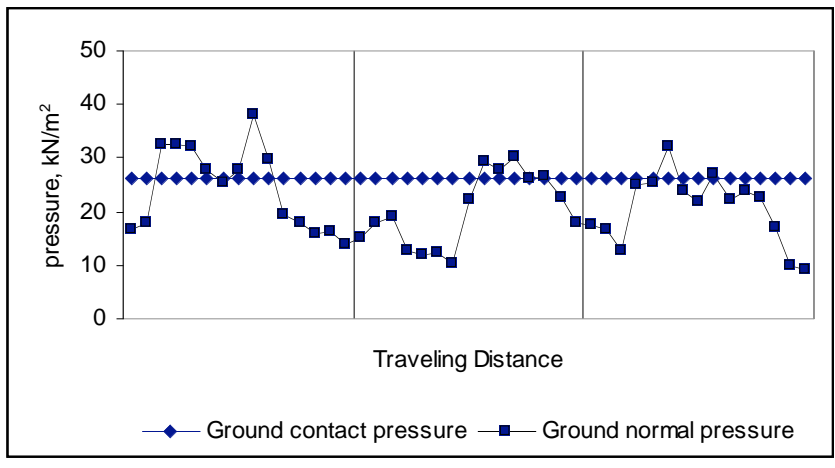

(b) LGP-30, vehicle weight $=34.5 \mathrm{kN}$

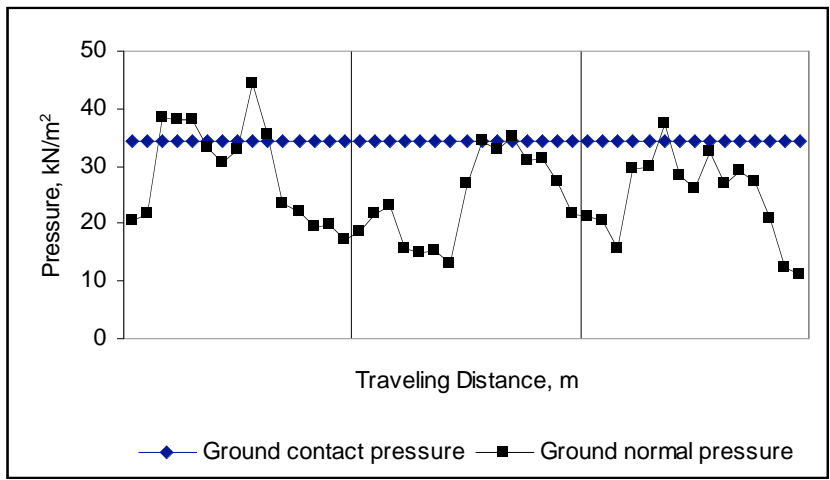

Fig. (8). Pressure distribution of the LGP-30 wheeled vehicle. the slippage of $20 \%, 30 \%$ and $40 \%$. Fig. (10) shows that the motion resistance is significantly higher than the traction of the vehicle, which could happen due to the excessive sinkage of tires.

(a) LGP-30, vehicle weight $=26 \mathrm{kN}$

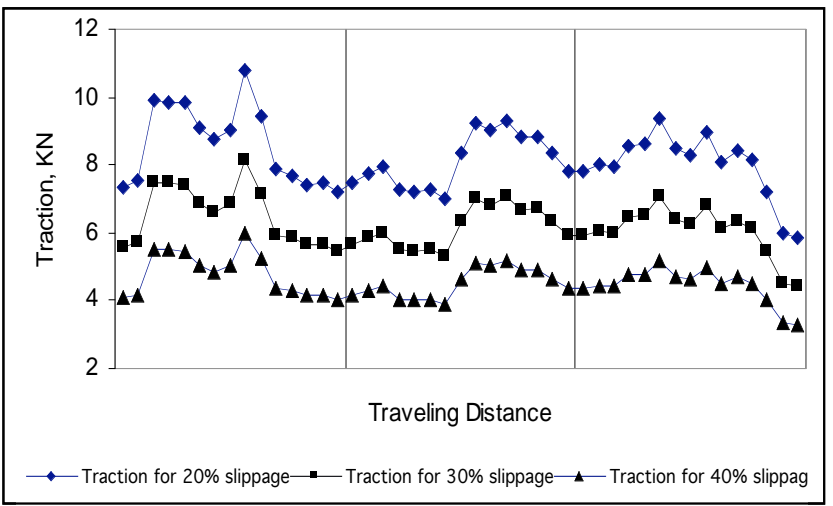

(b) LGP-30, vehicle weight $=34.5 \mathrm{kN}$

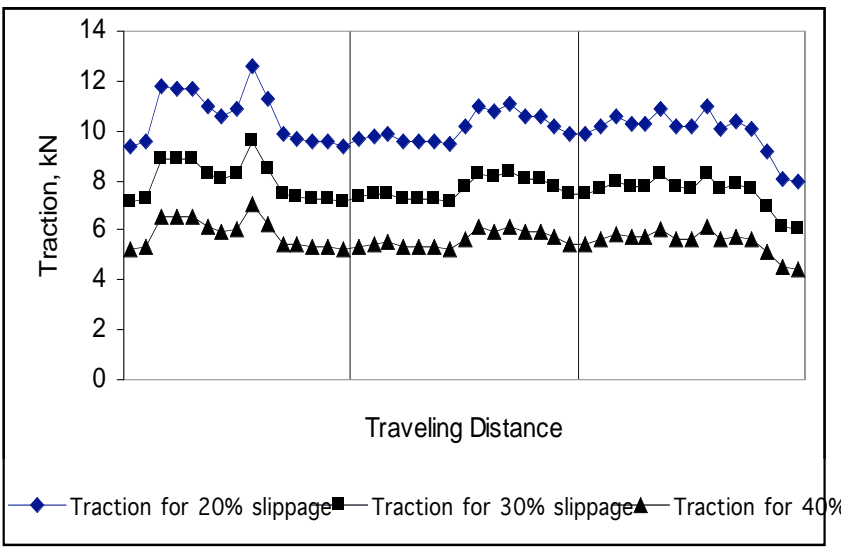

Fig. (9). Traction of the wheeled vehicle on Sepang peat terrain.

Furthermore, the simulation results presented in Figs. (510), show that the vehicle

- Sinkage is more than the critical sinkage of $0.12 \mathrm{~m}$

- $\quad$ Slippage is more than critical slippage of $40 \%$

- Ground contact pressure is more than the critical pressure of $17 \mathrm{kN} / \mathrm{m}^{2}$

- Rolling motion resistance due to terrain compaction is sometimes more than tractive force of the vehicle.

It is thus concluded that the vehicle would not be suitable to traverse on the peat terrain. The vehicle could be made suitable to operate on the low bearing capacity peat terrain either by

- $\quad$ Reducing $15 \%$ inflated pressure in order to increase the tire-terrain contact length by $40 \%$ and contact width by $35 \%$. The resulted vehicle's ground contact pressure and peat terrain's ground pressure are shown in Fig. (11).

- $\quad$ Reducing the LGP-30 wheeled vehicle total load to $9.81 \mathrm{kN}$ without payload and $19.62 \mathrm{kN}$ with $9.81 \mathrm{kN}$ payload. 
(a) LGP-30, vehicle weight $=26 \mathrm{kN}$

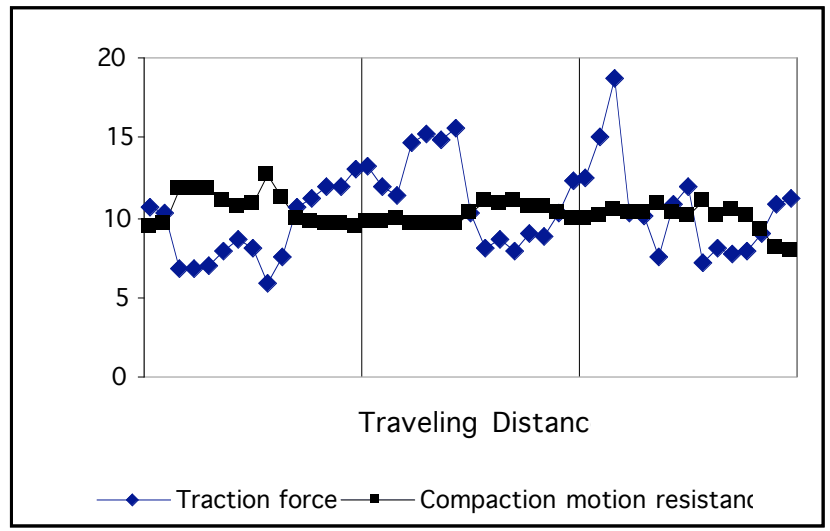

(b) LGP-30, vehicle weight $=34.5 \mathrm{kN}$

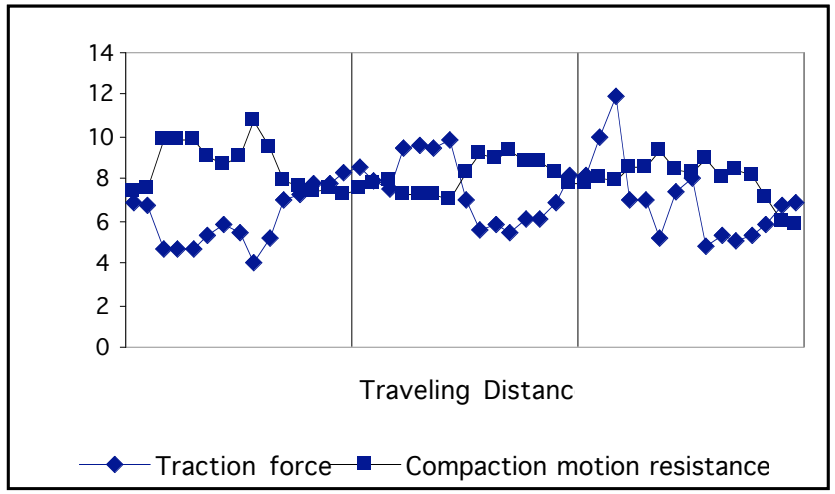

Fig. (10). Relationship between traction and motion resistance.

\subsection{Field Experimental Results}

The vehicle testing site was the unprepared moderate peat terrain at the Sepang, opposite of the Kuala Lumpur International Airport (KLIA), Malaysia. The important instrumentation system system are installed on the vehicle for conducting the field experiment on the vehicle tractive performance. The tractive force of the vehicle was measured by using the torque transducer and the traveling speed was set by using the K3GN-NDC-FLK DC24 digital panel meter. The slippage of the vehicle was conducted by measuring the vehicle actual speed by radar sensor and theoretical speed by electromagnetic-pick-up sensor. The motion resistance tests were not conducted due to the parking problem of the auxiliary vehicle. The straight motion tests of the vehicle were performed by increasing the vehicle's tyre-terrain contact part (flattened portion) with decreasing 5\%, 10\% and $15 \%$ tyre inflation pressure and two loading conditions of $26 \mathrm{kN}$ and $34.5 \mathrm{kN}$. Before each of the test, the vehicle was made ready by installing the portable generator set and the DEWE 2010 on the vehicle. The instrumentation system was tested by executing the developed programmed with DASY Lab 5.6 ${ }^{\circledR}$ into the DEWE-2010. Then, a preliminary run on the terrains was performed for ensuring the expected function of the instrumentation system of the vehicle. The field experiments were conducted on all over the field. Test I represented for a complete trips on one track while the Test II for the different track on the same field. Typical field experimental results of the $26 \mathrm{kN}$ and $34.5 \mathrm{kN}$ vehicle are shown in Figs. (12-15). The traveling speed of the vehi- cle during field test was considered $12 \mathrm{~km} / \mathrm{h}$ which is the recommended velocity of the vehicle for plantation (according to the Malaysia Airport Berhad Plantation' Operational Manager).

(a) LGP-30, vehicle weight $=26 \mathrm{kN}$

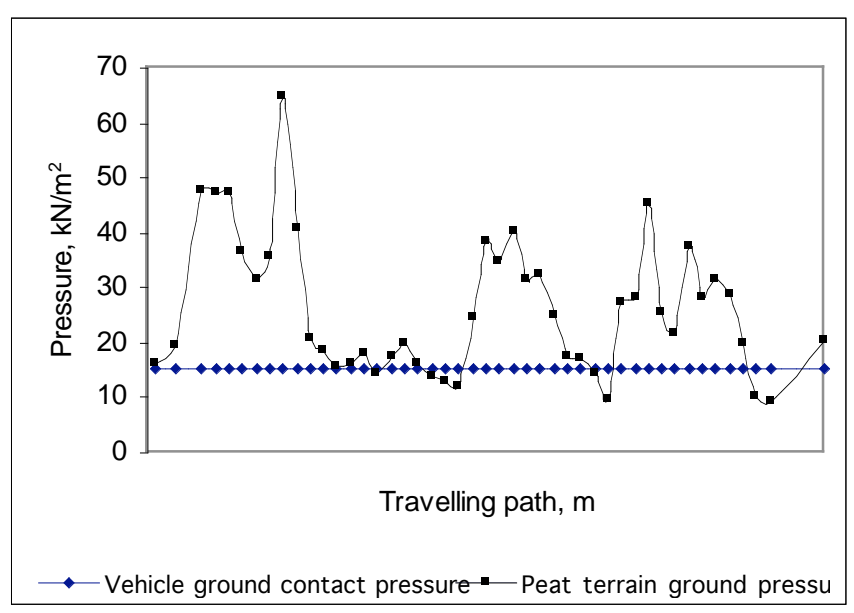

(b) LGP-30, vehicle weight $=34.5 \mathrm{kN}$

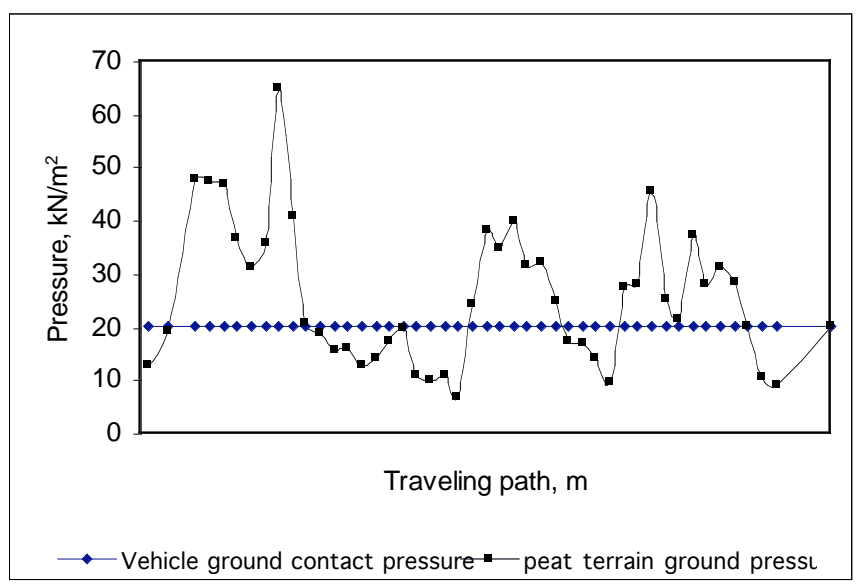

Fig. (11). Pressure relationship after decreasing $15 \%$ tyre inflation pressure.

The following brief discussions have been made based on the field experimental results:

\section{(i) For Vehicle Weight of $26 \mathrm{kN}$}

- It is found that the vehicle was stuck frequently when the tyre pressure was maximum as shown in Fig. (12). But, it was very rarely when the flattened portion was increased by decreasing the tyre inflation pressure of $5 \%$. While, the vehicle traversed effectively when its inflation pressure was reduced by $15 \%$.

- In the slippage and the tractive force relationship as shown in Fig. (13), it shows that the vehicle tyreground contact flattened incremental effect significantly increases the tractive effort and decreases the slippage. This conclusion could be justified by simplifying the Equation (32), which stated that the tractive effort of the vehicle is mainly the function of the vehicle tyre-ground contact area and the slippage. The terrain cohesiveness, internal friction angle, the shear deformation modulus could be not affect the tractive force significantly. While, the vehicle weight is con- 
stant. Furthermore, the incremental flattened portion of the tyre increased the vehicle floatation capacity.

(a)

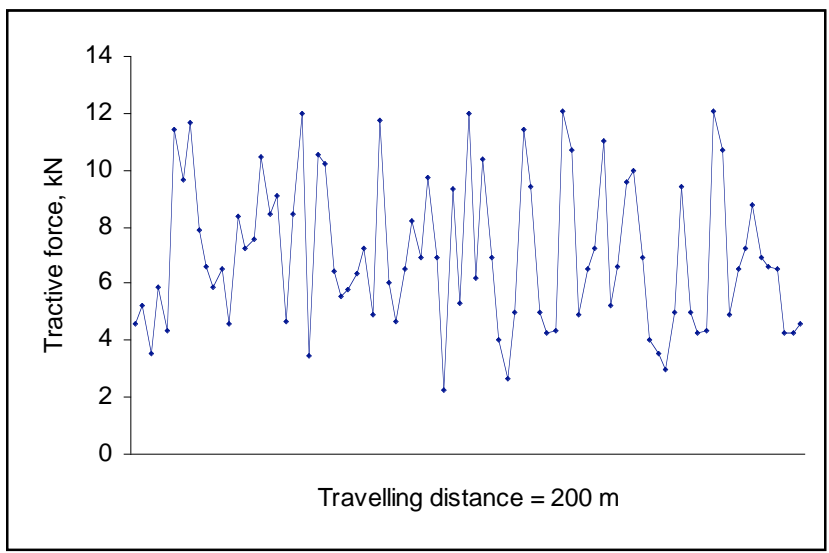

(b)

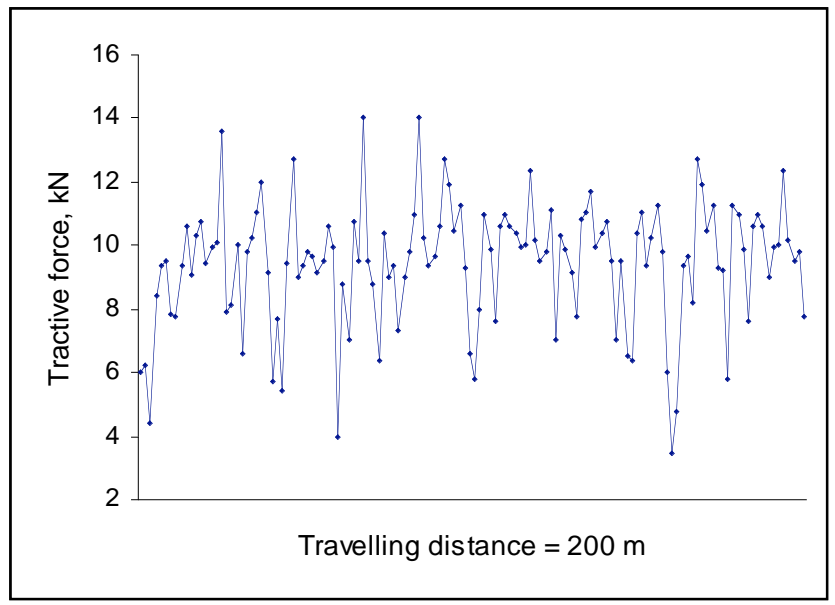

(c)

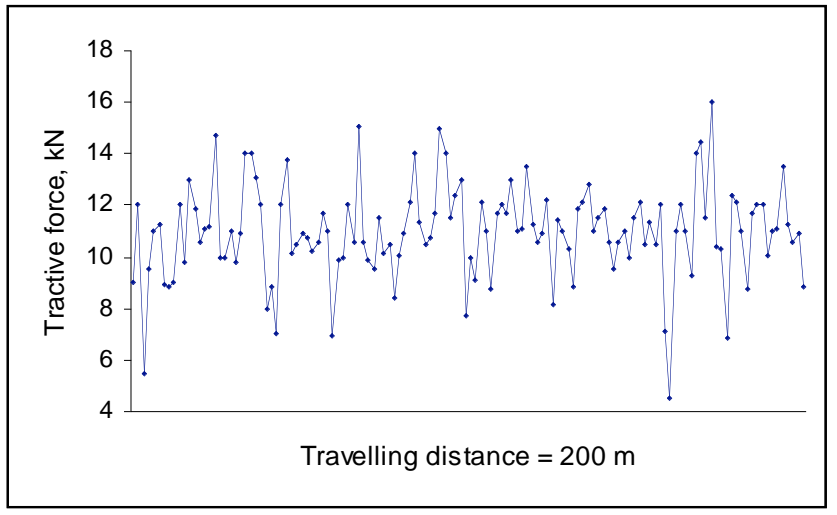

Fig. (12). $26 \mathrm{kN} \mathrm{LGP-30} \mathrm{wheeled} \mathrm{vehicle} \mathrm{typical} \mathrm{tractive} \mathrm{force} \mathrm{over}$ $200 \mathrm{~m}$ traveling distance with keeping constant the tyre-terrain contact part flattened by decreasing the tyre inflation pressure of (a) $5 \%$, (b) $10 \%$, and (c) $15 \%$.

\section{(ii) For Vehicle Weight of $34.5 \mathrm{kN}$}

- It is found that the vehicle was stuck almost all the times when the maximum tyre inflation pressure was used as shown in Fig. (14) and very frequently when the flattened portion was increased by decreasing the tyre inflation pressure of 5\%. It was also not traversed effectively even though its flattened portion was increased with decreasing the inflation pressure by 15\%. It is noted that the Fig. (14a) was constructed with avoiding the tractive force when the vehicle was in stuck.

(a)

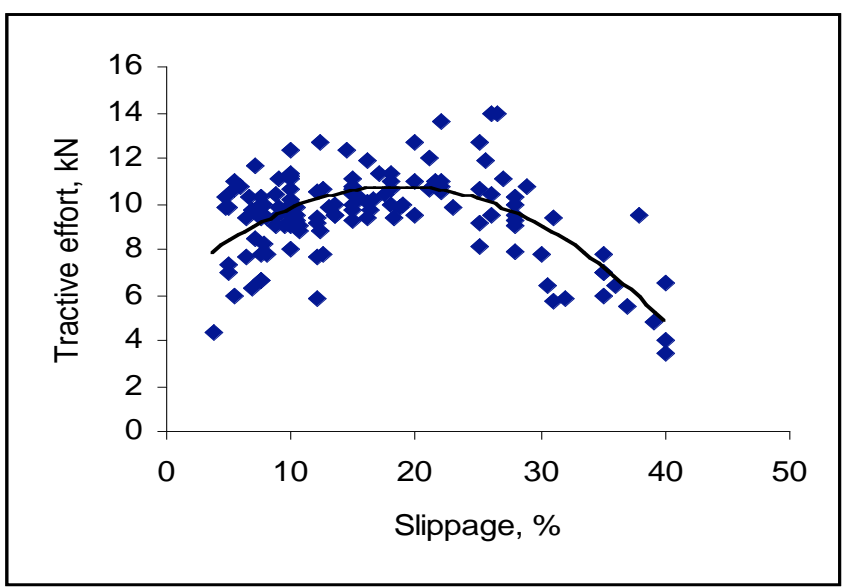

(b)

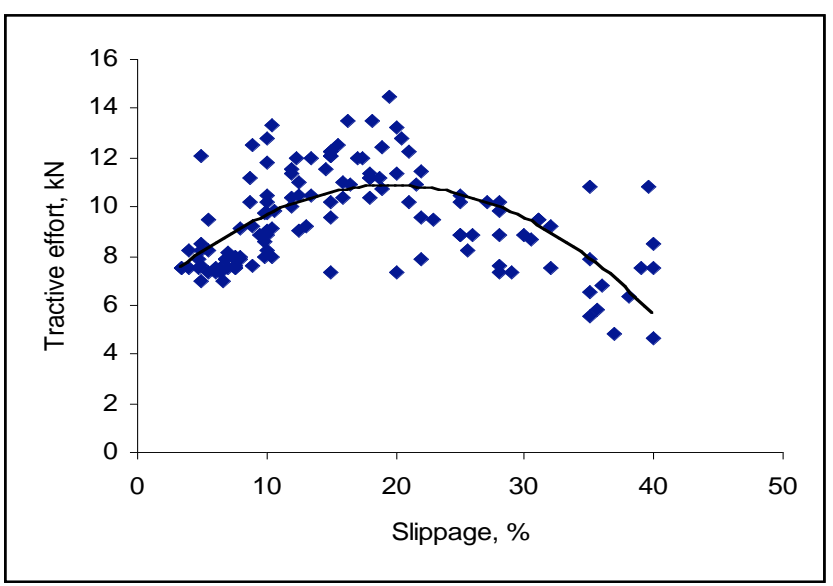

(c)

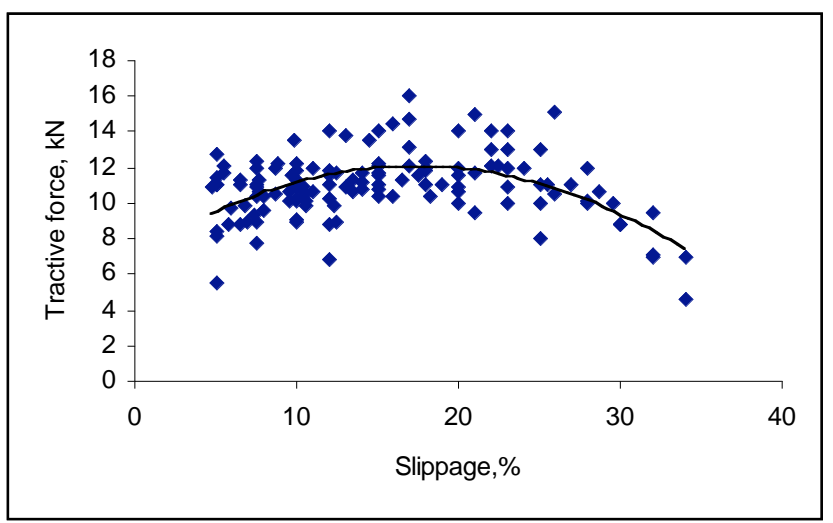

Fig. (13). $34.5 \mathrm{kN}$ LGP-30 wheeled vehicle typical tractive force and slippage relationship with keeping constant the tyre-terrain contact part flattened by decreasing the tyre inflation pressure of (a) $5 \%$, (b) $10 \%$, and (c) $15 \%$. 
(a)

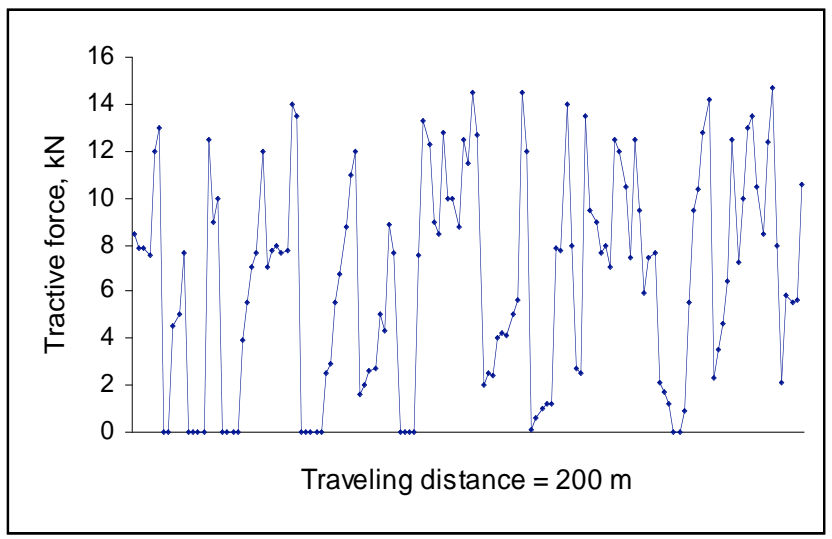

(b)

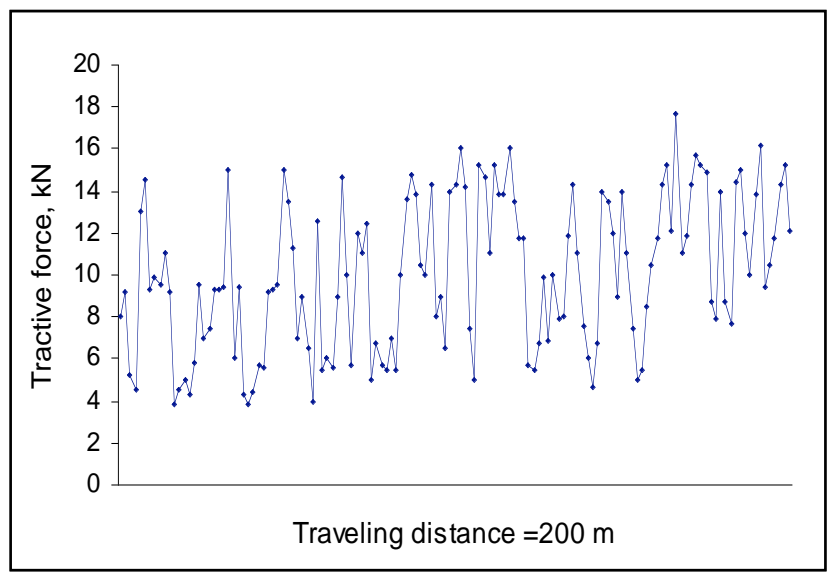

(c)

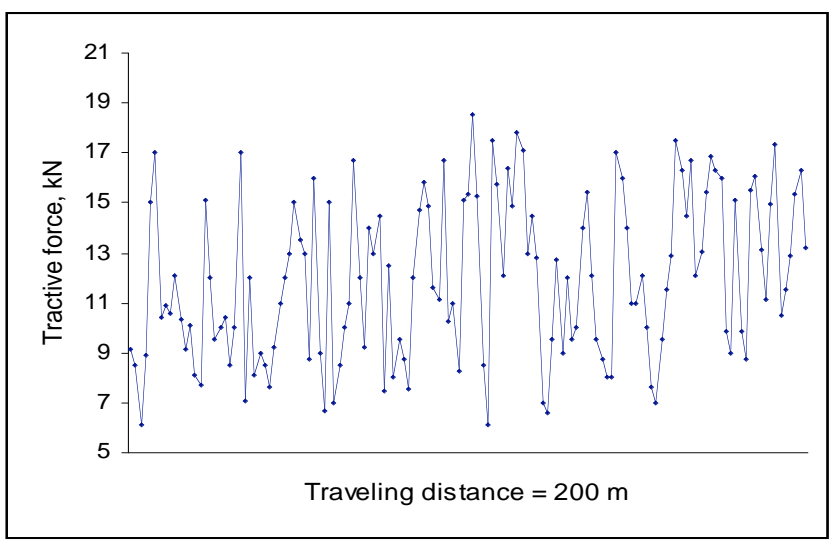

Fig. (14). $34.5 \mathrm{kN}$ LGP-30 wheeled vehicle typical tractive force over $200 \mathrm{~m}$ traveling distance with keeping constant the tyre-terrain contact part flattened by decreasing the tyre inflation pressure of (a) 5\%, (b) $10 \%$, and (c) $15 \%$.

- In the slippage and the tractive force relationship as shown in Fig. (15), it shows that the vehicle tyreground contact flattened incremental effect significantly increases the tractive force and decreases the slippage. But, the vehicle tractive force was found more than the tractive force for the vehicle of $26 \mathrm{kN}$. It was mainly for the variation of the vehicle weight. (a)

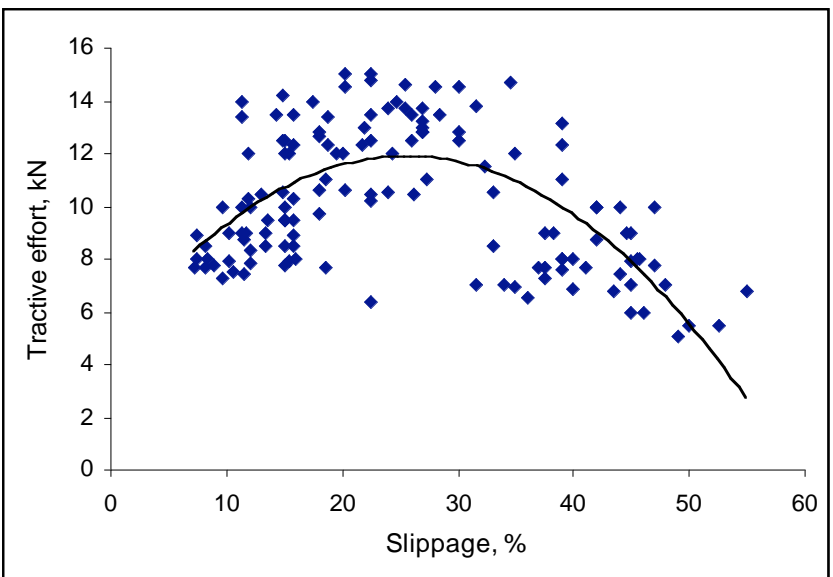

(b)

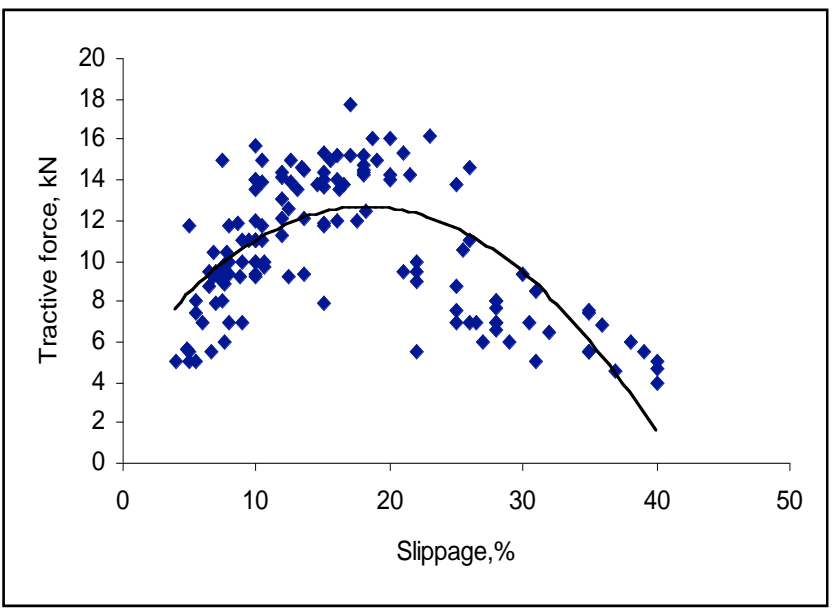

(c)

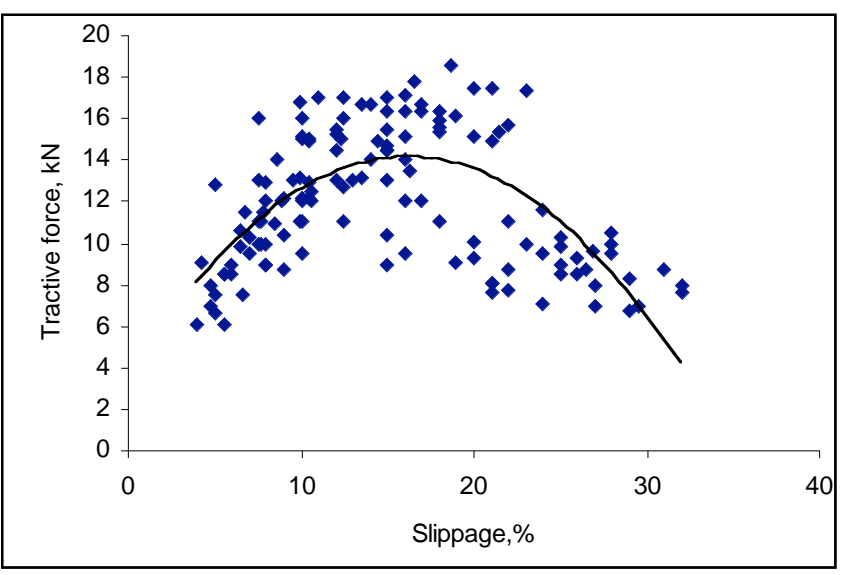

Fig. (15). $34.5 \mathrm{kN}$ LGP-30 wheeled vehicle typical tractive force and slippage relationship with keeping constant the tyre-terrain contact part flattened by decreasing the tyre inflation pressure of (a) $5 \%$, (b) $10 \%$, and (c) $15 \%$.

\section{MATHEMATICAL MODEL VALIDITY}

The validation of the developed mathematical model in this study was carried out by making comparison of the measured and predicted tractive performance of the vehicle 
(a) Vehicle weight $=26 \mathrm{kN}$

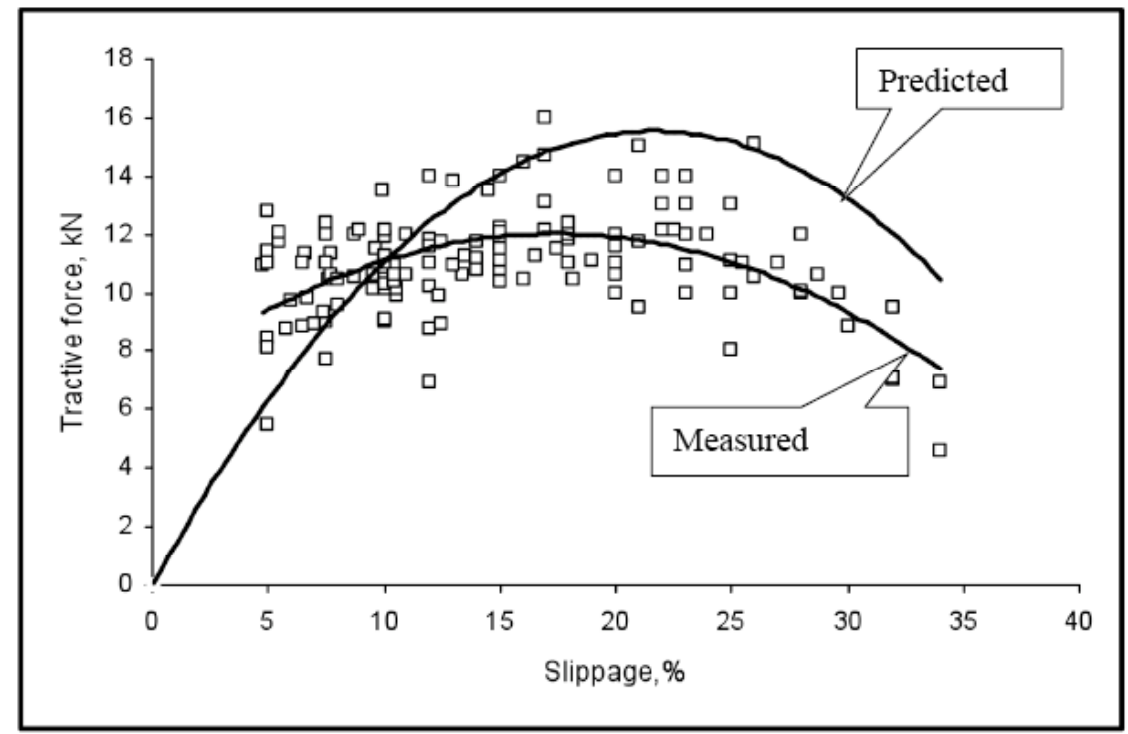

(b) Vehicle weight $=34.5 \mathrm{kN}$

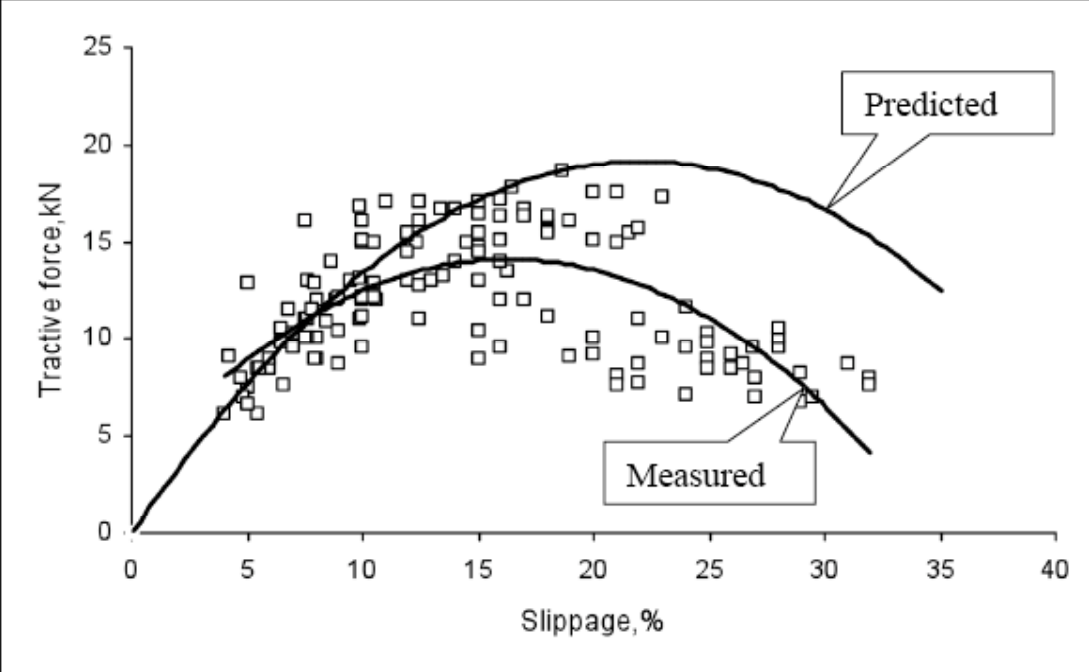

Fig. (16). LGP-30 wheeled vehicle tractive performance comparison keeping the tyre flattened portion constant by decrasing $15 \%$ tyre inflation pressure.

in straight motion for the loading conditions of $26 \mathrm{kN}$ and $34.5 \mathrm{kN}$ with increasing the tyre flattened portion by decreasing the tyre inflation pressure of $15 \%$. To validate the mathematical model, the vehicle tractive performance in terms of tractive force and slippage was measured and compared with the predicted ones. Fig. (16) shows the comparison of the predicted and measured tractive force for difference slippage during straight motion for the loading conditions of $26 \mathrm{kN}$ and $34.5 \mathrm{kN}$. The results indicate that there is less variability of the measured data and predicted data of the LGP-30 wheeled vehicle. It was found that the variability of the predicted data over the measured data is $19.2 \%$ and $23 \%$ for the vehicle loading conditions of $26 \mathrm{kN}$ and $34.5 \mathrm{kN}$, respectively. It indicates that the predicted data over the measured data has a closed agreement and thus the closed agreement could substantiate the validity of the mathematical model during straight motion.

\section{CONCLUSIONS}

Following conclusions could be drawn based on the content of this paper:

1. The new mathematical model on the slippage represents the proper function of the vehicle sinkage.

2. Sinkage and slippage increased with increasing of the terrain moisture content. It is noted that excessive sinkage of the vehicle causes the vehicle stuck which increased the vehicle slippage significantly.

3. Tractive effort of the vehicle changed over the travelling distance for the variation of the terrain cohesiveness $c$, internal friction angle $\varphi$, and the slippage of the terrain as the vehicle's operating load and the tire contact area are considered to be constant. It is reported in the authors earlier study ref. [8], the cohe- 
siveness and internal frictional angle are inversely proportional with the terrain moisture content.

4. Motion resistance of the vehicle changes with the variation of the terrain surface mat stiffness $m_{m}$, underlying peat stiffness $k_{p}$ and the sinkage as the vehicle operating load and the tire width are constant.

5. The simulation result also shows that the maximum tractive effort is $44.23,34.62$, and $23.85 \%$ of the vehicle weight for the slippage of 20,30 , and $40 \%$, respectively.

6. LGP-30 wheeled vehicle suitability for traversing on the moderate peat terrain could be justified by compromising the vehicle payload and the reduction $15 \%$ of the tyre inflation pressure for the tyre-terrain contact flattened part.

\section{REFERENCES}

J.Y. Wong, Theory of Ground Vehicles, (Third Edition), New York: John Willey \& Sons, Inc, 2001.
[2] J.Y. Wong, M. Garbar, and Preston-Thomas, "Theoritical prediction and experimental substantiation of the ground pressure distribution and tractive performance of tracked vehicles", J. Automob. Eng. Proc. IMech E Part D, vol. 15, pp. 65-85, 1984.

[3] G. Komandi, "Reevaluation of the adhesive relationship between the tire and the soil", J. Terramechanics, vol. 30, pp. 77-83, 1993.

[4] M.G. Bekker, and E.V. Semonin, "Motion resistance of pneumatic tires", J. Automot. Eng., vol. 06(2), pp. 6-10, 1975.

[5] M.G. Bekker, Introduction to terrain-vehicle systems. Ann Arbor, MI: University of Michigan Press, 1969.

[6] R. Ataur, Y. Azmi, and A.K.M. Mohiuddin, "Mobility investigation of a designed and developed segmented rubber track vehicle for sepang peat terrain in Malaysia", J. Automob. Eng. Proc. IMech E Part D, vol. 221 (D7), pp.789-800, 2007.

[7] R. Ataur, Y. Azmi, B. Zohaide, D. Ahmad, and W. Ishak, "Mechanical properties in relation to mobility of Sepang peat terrain in Malaysia", J. Terramechanics. vol. 41(01), pp. 25-40, 2004.

[8] R. Ataur, Y. Azmi, B. Zohadie, D. Ahmad, and W. Ishak, "Tractive performance of a designed and developed segmented rubber tracked vehicle on Sepang peat terrain during straight motion: theoretical analysis and experimental substantiation", Int. $J$. Heavy. Vehicle. Syst., vol. 13(04), pp. 298-323, 2006.

[9] R. Ataur, Y. Azmi, B. Zohadie, D. Ahmad, and W. Ishak, "Design and Development of a Segmented Rubber Tracked Vehicle for Sepang Peat Terrain in Malaysia", Int. J. Heavy Vehicle Syst. Indersci.. UK, vol. 12(03), pp. 239-267, 2005. 